\author{
Marquette University \\ e-Publications@Marquette
}

9-1999

\title{
Thermal Decomposition of Cross-linked Polybutadiene and its Copolymers
}

David D. Jiang

Marquette University

Galina F. Levchik

Belorussian State University

Sergei V. Levchik

Belorussian State University

Charles Wilkie

Marquette University, charles.wilkie@marquette.edu

Follow this and additional works at: https://epublications.marquette.edu/chem_fac

Part of the Chemistry Commons

\section{Recommended Citation}

Jiang, David D.; Levchik, Galina F.; Levchik, Sergei V.; and Wilkie, Charles, "Thermal Decomposition of Cross-linked Polybutadiene and its Copolymers" (1999). Chemistry Faculty Research and Publications. 750.

https://epublications.marquette.edu/chem_fac/750 


\section{Marquette University \\ e-Publications@Marquette}

\section{Chemistry Faculty Research and Publications/College of Arts and Sciences}

This paper is NOT THE PUBLISHED VERSION; but the author's final, peer-reviewed manuscript. The published version may be accessed by following the link in the citation below.

Polymer Degradation and Stability, Vol. 65, No. 3 (September, 1999): 387-394. DOI. This article is $($ Elsevier and permission has been granted for this version to appear in $\underline{\mathrm{e}}-$ Publications@Marquette. Elsevier does not grant permission for this article to be further copied/distributed or hosted elsewhere without the express permission from Elsevier.

\section{Thermal decomposition of cross-linked polybutadiene and its copolymers}

\section{David D.Jiang}

Department of Chemistry, Marquette University, Milwaukee, WI

Galina F.Levchik

Research Institute for Physical Chemical Problems, Belarussian State University, Belarus

Sergei V.Levchik

Research Institute for Physical Chemical Problems, Belarussian State University, Belarus Charles A.Wilkie

Department of Chemistry, Marquette University, Milwaukee, WI

\section{Abstract}

Polybutadiene and two copolymers containing butadiene and styrene have been cross-linked by thermal processes, by the use of initiators in solution, and by intimately mixing an initiator with the polymer and then heating this blend. The most efficient cross-linking process is the use of an intimate blend of the initiator and polymer. Most cross-linking processes lower the onset temperature of degradation, presumably because chain scission reactions occur 
simultaneously with cross-linking, while also increasing the fraction of non-volatile residue which is produced. It is believed that the density of cross-links is responsible for the increased yield of non-volatile residue.

\section{Introduction}

In previous work from these laboratories [1], it has been shown that ${ }^{60} \mathrm{Co}-\mathrm{y}$-ray irradiation will effect cross-linking of polybutadiene, PBD, but polystyrene, PS, can be cross-linked by irradiation only in the presence of oxygen. The thermal stability of ${ }^{60} \mathrm{Co}-\mathrm{y}$-ray-irradiated PBD is lower than that of unirradiated polymer while irradiated PS has enhanced thermal stability relative to the virgin polymer. Two butadiene-styrene block copolymers, SBS and K-resin, have also been cross-linked and here the thermal stability is related to the amount of PBD present in the polymer.

Polybutadiene actually undergoes cross-linking in the process of thermogravimetric analysis in an inert atmosphere and the cross-link density depends on the temperature and the time ${ }^{11}$. When a sample is heated to $400^{\circ} \mathrm{C}$, the cross-linking density is quite high. Thus thermogravimetric analysis of PBD is actually of a cross-linked sample which is quite similar to what is obtained by irradiation. The lower thermal stability of irradiated PBD must be due to radiation-induced degradation which produces fragments which are easily evolved during the thermal degradation.

In this paper the cross-linking of PBD, and related polymers is investigated by the use of purely thermal processes, by the use of chemical initiators, and by a combination of both, i.e. heating a sample in the presence of an initiator.

\section{Experimental}

\subsection{Materials}

Most chemicals and solvents in this study were supplied by Aldrich Chemical Company, including benzoyl peroxide (BPO), dicumyl peroxide (DCP), $t$-butyl peroxide (TBP); 2, 2'azobis(2-methylpropionitrile), AIBN, was obtained from Eastman Kodak Company.

The polymer used in this study was polybutadiene (PBD, MW: $2-3 \times 10^{6}$, containing $98 \%$ cis), supplied by Aldrich. Two copolymers of styrene and butadiene were used, styrene-butadienestyrene block copolymer, containing $75 \%$ butadiene, with a molecular weight of $5-10 \times 10^{5}$, supplied by Shell as Kraton D 1102 and herein referred to as SBS, and K-resin, supplied by Phillips Petroleum as KR01, containing about $75 \%$ styrene with a molecular weight of $5-$ $10 \times 10^{5}$. The polymers were used as received; films were cast by compression of the polymer beads at temperatures between 120 and $160^{\circ} \mathrm{C}$ and a pressure of about $8 \mathrm{MPa}$.

\subsection{Instrumentation}

Infrared spectra were obtained by transmission on a Mattson Galaxy Fourier Transform Infrared Spectrometer. Differential scanning calorimetry (DSC) and thermogravimetric analysis 
(TGA) were obtained using a Mettler model 3000 thermoanalyzer at a heating rate of $10^{\circ} \mathrm{C}$ per min, both in air and in an argon atmosphere; some thermogravimetric analysis was carried out on an Omnitherm 1000 TGA under a nitrogen atmosphere at a scan rate of 10 or $20^{\circ} \mathrm{C}$ per min. TGA/FTIR studies were carried out using a Cahn TG-131 balance interfaced to a Mattson Galaxy Fourier transform infrared spectrometer. The analysis was performed under inert atmosphere at a scan rate of $20^{\circ} \mathrm{C}$ per min.

\subsection{Thermal cross-linking}

The thin polymer films were placed in an ampoule and sealed under vacuum. These sample containers were then placed in a pre-heated oven maintained at either 100 or $150^{\circ} \mathrm{C}$ for times between 1 and 7 days. At the conclusion of the reaction time, the ampoules were removed and opened and the samples were removed and analyzed for gel content, swelling ratio and thermal stability. Thermal cross-linking in air was carried out by heating the samples on a watch glass in air.

\subsection{Solution cross-linking}

A $0.5 \mathrm{~g}$ polymer sample was dissolved in $20 \mathrm{ml}$ chloroform in a $50 \mathrm{ml}$ round bottom flask and then $0.5 \mathrm{ml}$ of a $0.20 \mathrm{M}$ acetone solution of benzoyl peroxide, BPO, was added. The sample was heated in an oil bath at $70^{\circ} \mathrm{C}$ for 3 to $24 \mathrm{~h}$. At the conclusion of the reaction, methanol was added to the contents of the flask to precipitate the polymer. After filtration to recover the polymer, the sample was thoroughly dried at room temperature and then gel content, swelling ratio, and thermal stability were measured. A similar reaction was carried out using dicumyl peroxide, DCP, as initiator in tetrachloeoethylene at $120^{\circ} \mathrm{C}$.

\subsection{Initiator-enhanced thermal cross-linking}

A $5.0 \mathrm{~g}$ sample of a polymer was dissolved in $50 \mathrm{ml}$ chloroform together with $20 \mathrm{mmol}$ BPO or DCP. After complete dissolution, the flask was stirred for $5 \mathrm{~min}$. This solution was then poured onto a teflon plate and the solvent was allowed to evaporate at room temperature for a minimum of 2 days. A $1.0 \mathrm{~g}$ sample of this mixture of polymer and initiator was sealed under vacuum in an ampoule. The sample was then placed in an oil bath which had been preheated to a temperature in the range of $70^{\circ} \mathrm{C}$ (for BPO) or $120^{\circ} \mathrm{C}$ (for DCP) for 3 to $24 \mathrm{~h}$. At the conclusion of the reaction, the ampoule was opened and the sample was removed and analyzed.

\subsection{Characterization of cross-linking}

The gel content and swelling ratio [2], [3], [4] were determined as previously described [1]. Gel content is determined by heating a sample of known mass in a solvent for $24 \mathrm{~h}$. The recovered insoluble sample is then thoroughly dried at elevated temperatures under vacuum and the mass of insoluble polymer is determined. The ratio of insoluble polymer to starting sample, expressed as percent, gives the fraction which has undergone gelation. Swelling ratio is determined by a similar process, after the heating period the insoluble sample is removed and 
then its mass is obtained. The ratio of solvent swollen sample to that of the starting sample is defined as the swelling ratio and is a measure of the cross-link density.

\section{Results and discussion}

\subsection{Thermal cross-linking}

All three polymers which have been examined in this study, polybutadiene, SBS and K-resin were heated in vacuum at a temperature of both 100 and $150^{\circ} \mathrm{C}$. No cross-linking of any of these three polymers was observed at $100^{\circ} \mathrm{C}$. At $150^{\circ} \mathrm{C}$ no cross-linking was observed for SBS and K-resin. For PBD cross-linking was observed at 2, 3, 4, and 7 days. The gel contents were 95\% for all cross-linked PBD samples and the swelling ratios were constant at about 4000 . This is interpreted to mean that PBD completely cross-links within 2 days and further heating does not change the extent of cross-linking. It is surprising to observe that neither SBS nor Kresin will undergo a cross-linking reaction by heating at $150^{\circ} \mathrm{C}$ while $\mathrm{PBD}$ does undergo such a reaction. From the previous work on this topic, all three butadiene-containing polymers undergo cross-linking at $400^{\circ} \mathrm{C}$ and the cross-link density is significantly higher than observed for PBD in this study. Cross-linking normally occurs by the coupling of two backbone radicals [5], the observation that no cross-linking occurs may mean that PS acts as an 'inhibitor' which prevents the radicals produced from the PBD portion from further reaction. The absence of cross-linking may also be due to the lower mobility of the macromolecular chains in SBS and K-resin.

\subsection{The effect of oxygen on cross-linking}

When the cross-linking reaction is carried out in air, the course of the reaction is quite different. The cross-linking reaction is essentially complete for PBD at $150^{\circ} \mathrm{C}$ after 1 day and the swelling ratio decreases as the time of reaction increases. For both SBS and K-resin some cross-linking occurs after 1 day and the gel content increases with time. A somewhat similar situation occurs at $100^{\circ} \mathrm{C}$ and the data in shown in Table 1.

Table 1. Thermal Cross-linking of PBD, SBS, and K-resin at 100 and $150^{\circ} \mathrm{C}$ in air

\begin{tabular}{|lllllll|}
\hline $\begin{array}{c}\text { Time } \\
\text { (days) }\end{array}$ & $\begin{array}{c}\text { PBD (\% } \\
\text { GC) }\end{array}$ & $\begin{array}{c}\text { PBD (\% } \\
\text { SR) }\end{array}$ & $\begin{array}{c}\text { SBS (\% } \\
\text { GC) }\end{array}$ & $\begin{array}{c}\text { SBS (\% } \\
\text { SR) }\end{array}$ & $\begin{array}{c}\text { K-resin (\% } \\
\text { GC) }\end{array}$ & $\begin{array}{c}\text { K-resin (\% } \\
\text { SR) }\end{array}$ \\
At $100^{\circ} \mathrm{C}$ & & & & & & \\
0 & & & 0 & & 0 & \\
1 & 0 & & 28 & 3100 & 0 & \\
2 & 0 & & 40 & 3000 & 0 & \\
3 & 0 & & 47 & 2000 & 0 & \\
4 & 0 & & 52 & 1600 & 0 & \\
5 & 18 & 5200 & 56 & 1300 & 0 & \\
7 & 95 & 2400 & 63 & 1100 & 32 & 2900 \\
\hline
\end{tabular}




\begin{tabular}{|lllllll|}
\hline $\begin{array}{c}\text { Time } \\
\text { (days) }\end{array}$ & $\begin{array}{c}\text { PBD (\% } \\
\text { GC) }\end{array}$ & $\begin{array}{c}\text { PBD (\% } \\
\text { SR) }\end{array}$ & $\begin{array}{c}\text { SBS (\% } \\
\text { GC) }\end{array}$ & $\begin{array}{c}\text { SBS (\% } \\
\text { SR) }\end{array}$ & $\begin{array}{c}\text { K-resin (\% } \\
\text { GC) }\end{array}$ & $\begin{array}{c}\text { K-resin (\% } \\
\text { SR) }\end{array}$ \\
At $150^{\circ} \mathrm{C}$ & & & & & & \\
0 & 0 & & 0 & & 0 & \\
1 & 94 & 2500 & 35 & 4500 & 33 & 3500 \\
2 & 98 & 1200 & 55 & 2400 & 81 & 1700 \\
3 & 99 & 1100 & 62 & 1800 & 84 & 900 \\
4 & 99 & 1000 & 88 & 1700 & 85 & 800 \\
5 & 99 & 900 & 85 & 1500 & 87 & 800 \\
7 & 99 & 700 & 86 & 1400 & 86 & 800 \\
\hline
\end{tabular}

The cross-linking behavior of SBS is anomalous; partial cross-linking is observed after 1 day at $100^{\circ} \mathrm{C}$ while PBD requires 5 days and the gel content is lower and the cross-link density is higher. At $150^{\circ} \mathrm{C}$ PBD cross-links more efficiently than either SBS or K-resin, the expected behavior based on the butadiene content.

The results reported above clearly show that the presence of oxygen enhances the crosslinking of PBD. Infrared spectra of the cross-linked samples were obtained in order to ascertain the role of oxygen in the process. Upon irradiation in the presence of air, peroxide, hydroxide and carbonyl groups are found in the polymers [6], [7]. A similar reaction may occur when PBD is heated in air. From a comparison of the virgin sample, a sample cross-linked in vacuum, and one cross-linked in air, three features in the air cross-linked samples can be seen which are absent in the other two samples: a strong band at $3430 \mathrm{~cm}^{-1}$, which may be assigned to the $\mathrm{O}-\mathrm{H}$ stretching vibration and two bands at 1202 and $1047 \mathrm{~cm}^{-1}$, which may be due to the $\mathrm{C}-\mathrm{O}$ stretching frequency $[8]$. Oxygen may be incorporated in the polymer either at an allylic position or at the carbon-carbon double bond and oxidation at the allylic position is more likely.

There are several steps in the thermal degradation of PBD [1], cis-trans isomerization [1], [9], [10], occurs around $250^{\circ} \mathrm{C}$ while cyclization and cross-linking occur at about $370^{\circ} \mathrm{C}$ [9], [10], [11], [12], [13], [14], [15]. Since these reactions are performed at 100 or $150^{\circ} \mathrm{C}$, there may be some isomerization. In a very recent paper, Zeng and Ko have cross-linked PBD at ultrahigh pressures; they have further proposed a pathway for the cis-trans isomerization [16]. It is also possible that some chain scission occurs and this may lead to cyclization. The infrared spectrum of PBD cross-linked under vacuum confirms that isomerization occurs. PBD contains $98 \%$ cis-1,4-, with smaller amounts of the trans-1,4-, and 1,2 - vinyl linkages [17]. Cis-1,4-PBD shows a broad strong $\mathrm{C}-\mathrm{H}$ out-of-plane bending mode at $740 \mathrm{~cm}^{-1}$, while in trans-1,4-isomer this band is at $965 \mathrm{~cm}^{-1}$ and is much sharper, and the 1, 2-vinyl isomer shows two bands: vinyl $\mathrm{CH}$ at 995 and vinyl $\mathrm{CH}_{2}$ at $912 \mathrm{~cm}^{-1}[9],[10]$. When PBD is cross-linked under vacuum at $150^{\circ} \mathrm{C}$ the band at $740 \mathrm{~cm}^{-1}$ decreases in intensity while the band at $965 \mathrm{~cm}^{-1}$ grows; isomerization from cis to trans occurs at $150^{\circ} \mathrm{C}$. For the samples cross-linked under air, the band at $740 \mathrm{~cm}^{-1}$ becomes weaker while that at $965 \mathrm{~cm}^{-1}$ is not seen. This may be interpreted to mean that the double bond is opened in the cross-linking reaction or it may mean that oxidation of allylic hydrogens occurs and the position of absorption of the $\mathrm{C}-\mathrm{H}$ deformation modes is shifted to a 
new position. When the reaction is conducted in vacuum, no reactive species are present and the double bond reforms in the more stable trans form.

A possible scheme to account for the destabilization and cross-linking of PBD is shown below in Eq. (1). A series of hydrogen transfer reactions may occur in PBD when it is heated in the absence of oxygen. Transfer of allylic hydrogen can lead to the chain scissions [9], [18], and the newly formed vinyl chain ends can undergo either cyclization [9] or cross-linking through a branching ${ }^{[1]}$ reaction.

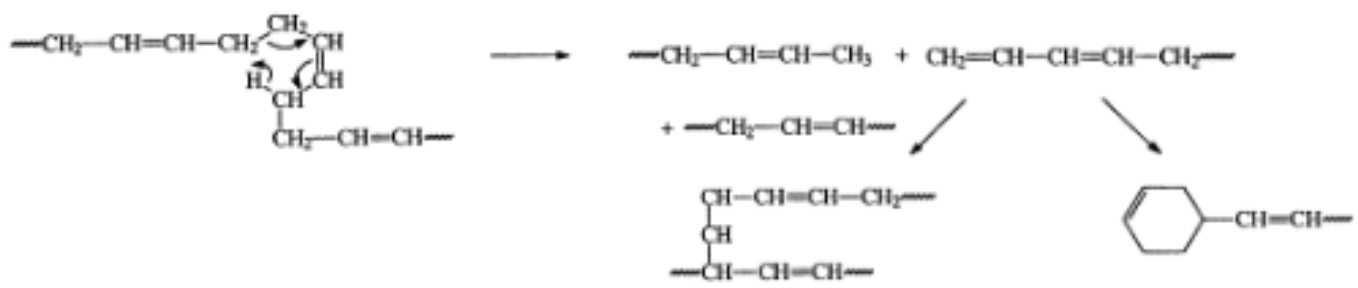

In the presence of air, oxygen reacts with the radicals produced by the opening of the double bond, probably initially giving either a peroxy linkage or an epoxy linkage. These are cleaved and undergo hydrogen abstraction reactions to form the observed $\mathrm{C}-\mathrm{O}$ and $\mathrm{O}-\mathrm{H}$ bonds.

SBS shows a quite different cross-linking behavior compared to PBD, possible due to the presence of additives which are present in the polymer or to differences in the structure of the PBD blocks. The additives which are present in SBS, as determined from the MSDS, are antioxidants, stabilizers, and calcium carbonate.

The antioxidants and stabilizers were removed by repetitively soaking the SBS in acetone and then recovery of the polymer by filtration. A comparison of the cross-linking of polymer as received and after extraction is shown in Table 2. The cross-linking behavior is different for the two samples. After removal of additives, the gel content is higher while the cross-link density does not change.

Table 2. Comparison of the cross-linking behavior of virgin SBS and SBS with stabilizer removed in air

\begin{tabular}{|lllll|}
\hline $\begin{array}{c}\text { Time } \\
\text { (days) }\end{array}$ & $\begin{array}{c}\text { Untreated SBS (\% } \\
\text { GC) }\end{array}$ & $\begin{array}{c}\text { Untreated SBS (\% } \\
\text { SR) }\end{array}$ & $\begin{array}{c}\text { Treated SBS (\% } \\
\text { GC) }\end{array}$ & $\begin{array}{c}\text { Treated SBS (\% } \\
\text { SR) }\end{array}$ \\
0 & 0 & & 0 & 2900 \\
1 & 28 & 3100 & 55 & 2900 \\
2 & 40 & 3000 & 77 & 2900 \\
3 & 47 & 2000 & 90 & 2800 \\
4 & 52 & 1600 & 89 & 2800 \\
5 & 56 & 1400 & 92 &
\end{tabular}




\begin{tabular}{|c|c|c|c|c|}
\hline $\begin{array}{l}\text { Time } \\
\text { (days) }\end{array}$ & $\begin{array}{c}\text { Untreated SBS (\% } \\
\text { GC) }\end{array}$ & $\begin{array}{c}\text { Untreated SBS (\% } \\
\text { SR) }\end{array}$ & $\begin{array}{c}\text { Treated SBS (\% } \\
\text { GC) }\end{array}$ & $\begin{array}{c}\text { Treated SBS (\% } \\
\text { SR) }\end{array}$ \\
\hline 7 & 63 & 1000 & 90 & 2900 \\
\hline
\end{tabular}

The structure of PBD portion of SBS can be identified by infrared spectroscopy, because of the different out-of-plane bending modes as noted above. Only the band at $965 \mathrm{~cm}^{-1}$ is observed in the infrared spectrum of SBS and thus SBS contains only, or mainly, trans units and is therefore quite different from PBD. The infrared spectrum of K-resin shows a somewhat weak band at $965 \mathrm{~cm}^{-1}$ the band at $740 \mathrm{~cm}^{-1}$ is obscured by styrene vibrations and cannot be observed. K-resin behaves more like PBD than SBS when cross-linked at $100^{\circ} \mathrm{C}$; this would indicate that K-resin contains largely cis butadiene units. Based upon the infrared and gelation measurements, it is reasonable to assume that this product is largely cis, yet with some trans component. Finally the presence of polystyrene may have an effect of the cross-linking behavior.

Three new bands, at 3416, 1720, and $1042 \mathrm{~cm}^{-1}$, are observed in the infrared spectrum of SBS which has been cross-linked in air. These bands show that oxygen participates in the cross-linking reaction of SBS in air. The presence of a carbonyl at $1720 \mathrm{~cm}^{-1}$ is indicative of the presence of either an aldehyde or ketone and is what one might expect from the oxidative degradation of butadiene ${ }^{[19]}$. The other two frequencies are due to the $\mathrm{O}-\mathrm{H}$ and $\mathrm{C}-\mathrm{O}$ stretching frequencies, as also observed in PBD. The $\mathrm{C}-\mathrm{H}$ stretching frequency at $3007 \mathrm{~cm}^{-1}$ has a decreased intensity in the cross-linked sample and this band is due to the olefinic $\mathrm{C}-\mathrm{H}$ so this means that the reaction occurs at the double bond site. Thus the same reaction occurs upon cross-linking of both PBD and SBS.

The accelerated cross-linking of SBS might be explained by the presence of 1,2-butadiene fragments. Pendant vinyl groups tend to react with radicals producing cross-links, whereas vinylene groups easily lose allylic hydrogen producing relatively ureactive radicals [20]. These radicals dominantly react with oxygen giving peroxides, with decomposition leading to chain scission. Some of allylic radicals recombine resulting in cross-links, which explain gelation of PBD [Eq. (2)]. 


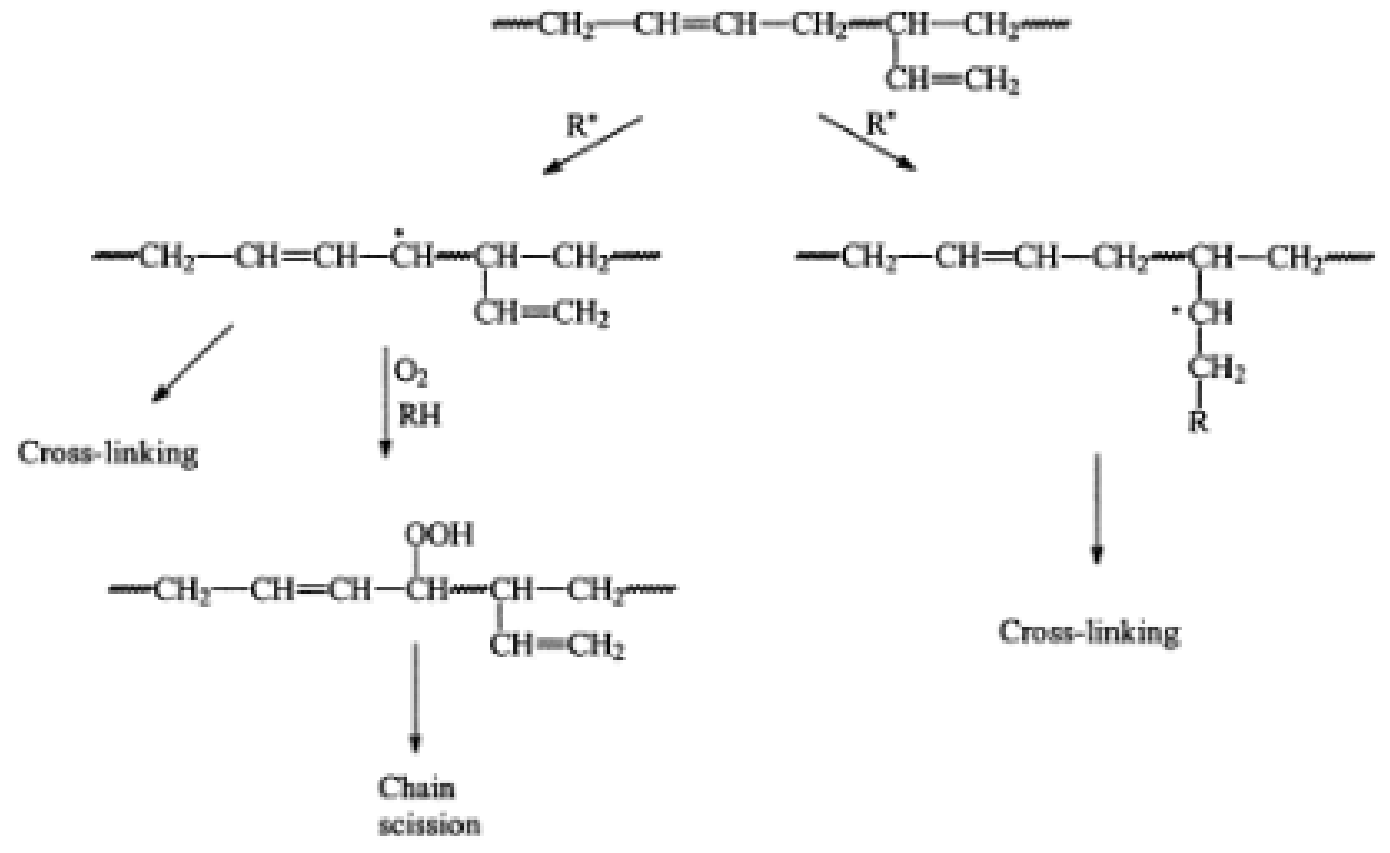

(2)

\subsection{The effect of cross-linking on thermal stability}

The thermal stability of the cross-linked polymers was evaluated by thermogravimetric analysis and differential scanning calorimetry. The regions of interest in the TGA curves are the onset temperature, evaluated as the temperature at which $10 \%$ mass loss occurs, and fraction which is non-volatile at high temperature. The TGA curves for PBD and cross-linked PBDs are shown in Fig. 1. One can see that degradation begins earlier in the cross-linked samples than in the virgin polymer and there is more non-volatile residue from the cross-linked samples than from the virgin sample. Samples which have been cross-linked in air give TGA curves which are virtually identical with those cross-linked in vacuum. The irradiation of PBD also produced the same results [1]; here it was suggested that irradiation effected the formation of some small fragments which were easily evolved but that after their evolution the degradation continued relatively unaffected by the cross-linking. It is likely that a similar explanation holds here. The presence of an initiator is likely to cause some bond scission with the formation of some small fragments. These small fragments evolve and the onset temperature of degradation is lower while the extensively cross-linked material leads to a higher non-volatile fraction at $600^{\circ} \mathrm{C}$. The amount of such small fragments must be quite significant since more than $10 \%$ degradation occurs. PBD undergoes cross-linking in the course of thermogravimetric analysis so there is no difference at elevated temperatures between the cross-linked samples prepared in this study and virgin PBD except, perhaps, in the extent of cross-linking. From the enhanced non-volatile residue it is clear that the extent of cross-linking is important in char formation. 


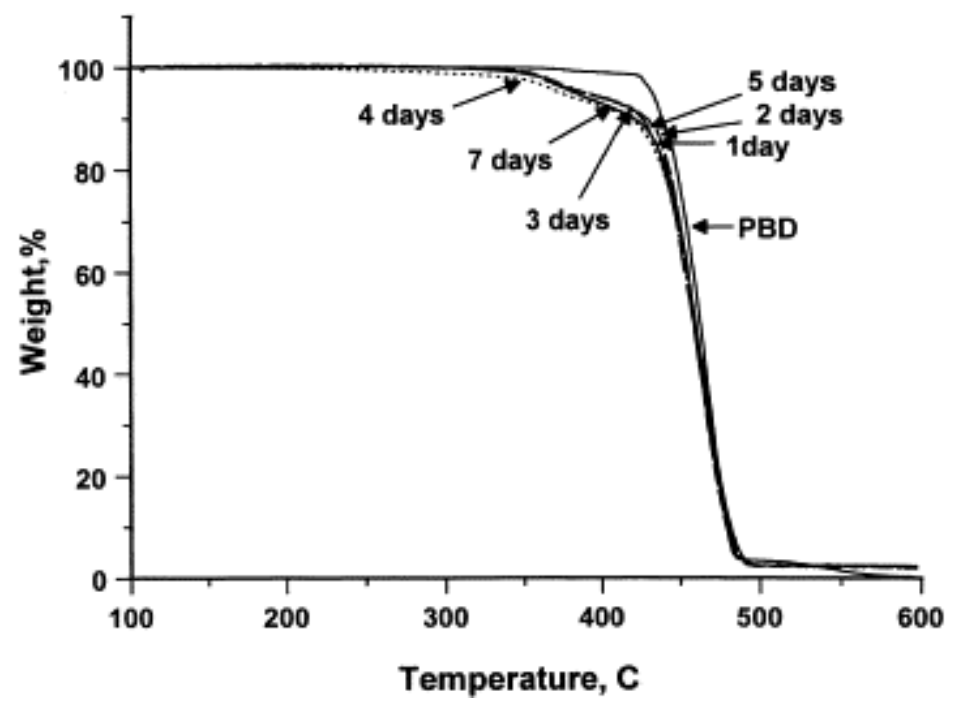

Fig. 1. TGA curves for PBD and PBD which has been heated for the indicated time in inert atmosphere.

Similar results are obtained for the cross-linking of SBS; Fig. 2, Fig. 3 show the TGA curves for samples which have been cross-linked in air at $100^{\circ} \mathrm{C} \mathrm{(Fig.} \mathrm{2)} \mathrm{and} 150^{\circ} \mathrm{C}$ (Fig. 3). There is a significant difference in the thermal stability depending upon the temperature of cross-linking. When the cross-linking reaction occurs at $100^{\circ} \mathrm{C}$, degradation begins much earlier but a larger amount of transitory char is formed at about $450^{\circ} \mathrm{C}$; this has essentially entirely volatilized by $600^{\circ} \mathrm{C}$. For cross-linking at $150^{\circ} \mathrm{C}$, the degradation does commence earlier but by the time about $30 \%$ of the sample has volatilized there is little, if any, difference between virgin and cross-linked SBS. It is known that no cross-linking of polystyrene occurs so any differences between these copolymers must be attributable to the butadiene content [21]. The TGA curves for K-resin are quite similar to those of SBS which has been cross-linked at $150^{\circ} \mathrm{C}$, i.e. there is little difference between virgin and cross-linked polymer. There is no apparent difference in thermal stability between SBS which has had stabilizers, etc., removed and one which contains these additives.

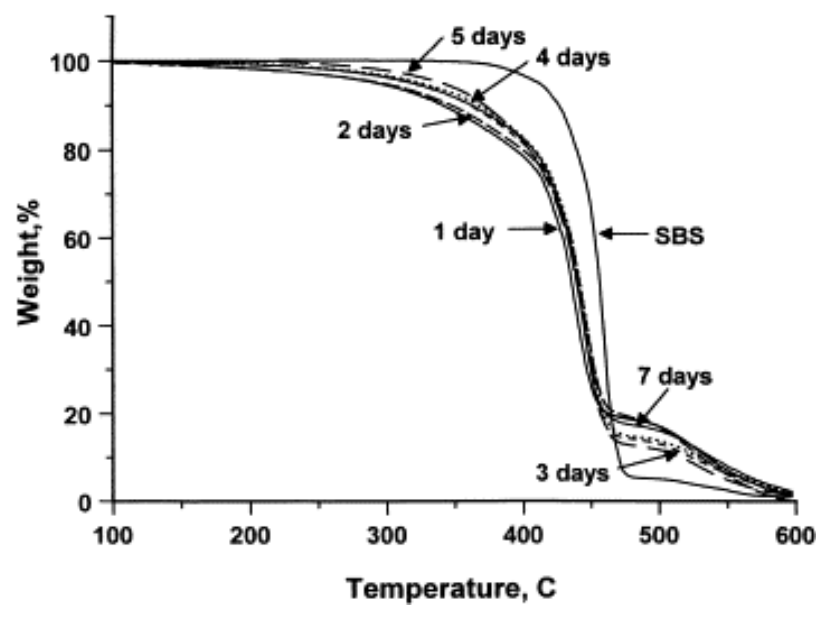

Fig. 2. TGA curves for SBS cross-linked at $100^{\circ} \mathrm{C}$ in air for the indicated time. 


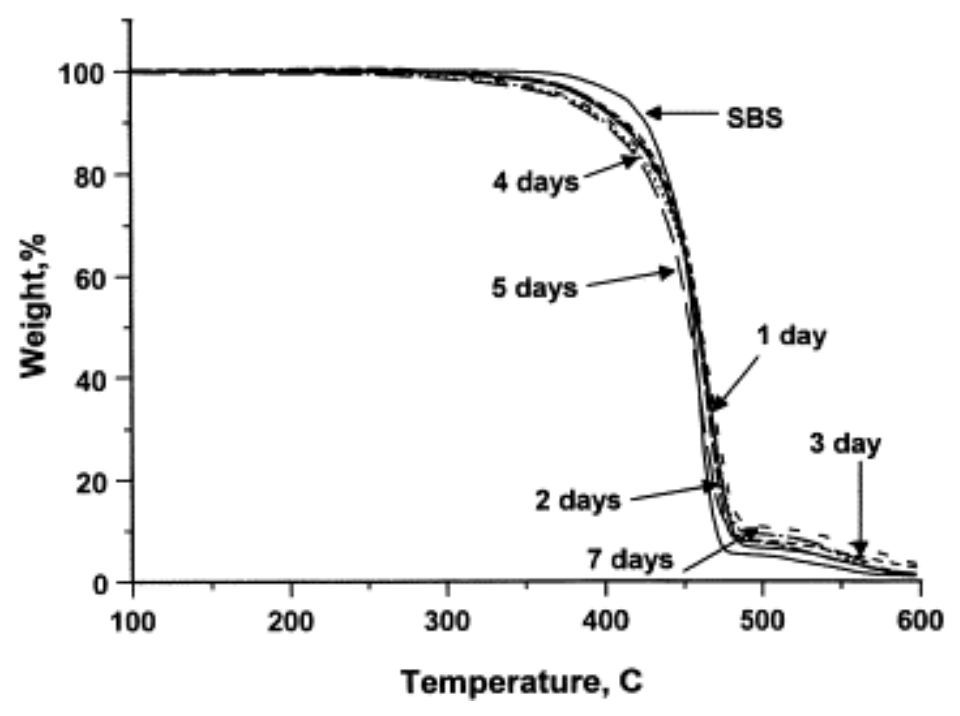

Fig. 3. SBS cross-linked in air at $150^{\circ} \mathrm{C}$ for the indicated time.

When the thermogravimetric analysis is performed in air there is almost no difference between virgin and cross-linked polymers. The onset of degradation occurs at the same temperature and there is no non-volatile residue produced.

There are three features in the DSC curve of PBD, cis-trans isomerization near $220^{\circ} \mathrm{C}$, cyclization at about $380^{\circ} \mathrm{C}$, and the degradation endotherm at about $480^{\circ} \mathrm{C}$. The first of these, isomerization, vanishes after cross-linking while the cyclization and degradation steps are virtually unchanged. This indicates that isomerization always occurs upon cross-linking, as also shown by infrared evidence. The presence of the cyclization feature is indicative of low cross-link density. If there were extensive cross-linking it is difficult to imagine how the polymer would have enough mobility to undergo cyclization; this has been seen in previous work on irradiation [1]. Likewise the DSC curves of SBS and K-resin are little changed by the crosslinking reaction.

\subsection{Solution cross-linking processes}

\subsubsection{Cross-linking behavior}

All three polymers have been cross-linked by refluxing a chloroform solution of the polymer in the presence of benzoyl peroxide, BPO. In all cases cross-linking does occur and significantly more quickly than from a simple thermal process. More time is required to cross-link SBS and $\mathrm{K}$-resin than PBD and this may reflect some inhibition from the styrene portion of the copolymers or the presence of 1,2-isomers in these commercial products. The swelling ratios are higher at a given gel content than is observed from the strictly thermal process; molecules which are in solution are most likely to encounter the initiator and react and lightly cross-linked species will precipitate and thus be unavailable for further reaction. The gel contents and swelling ratios are shown in Table 3. 
Table 3. Gel contents and swelling ratios for PBD, SBS, and K-resin cross-linked in solution with benzoyl peroxide

\begin{tabular}{|lllllll|}
\hline $\begin{array}{l}\text { Time } \\
\text { (h) }\end{array}$ & $\begin{array}{c}\text { PBD (\% } \\
\text { GC) }\end{array}$ & $\begin{array}{c}\text { PBD (\% } \\
\text { SR) }\end{array}$ & $\begin{array}{c}\text { SBS (\% } \\
\text { GC) }\end{array}$ & $\begin{array}{c}\text { SBS (\% } \\
\text { SR) }\end{array}$ & $\begin{array}{c}\text { K-resin (\% } \\
\text { GC) }\end{array}$ & $\begin{array}{c}\text { K-resin (\% } \\
\text { SR) }\end{array}$ \\
0 & 0 & & 0 & & 0 & \\
3 & 41 & 11000 & 0 & & 0 & \\
6 & 92 & 3000 & 0 & & 0 & \\
8 & - & - & 69 & 4900 & 84 & 3700 \\
12 & 98 & 3000 & 94 & 4500 & 86 & 4000 \\
24 & 99 & 3000 & 98 & 3200 & 94 & 3400 \\
\hline
\end{tabular}

Reactions have also been carried out using both dicumyl peroxide, DCP, and di-t-butyl peroxide, TBP, as initiator. These reactions were carried out in tetrachloroethylene as solvent since both DCP and TBP have half-lives at $120^{\circ} \mathrm{C}$, the boiling point of the solvent, which are roughly comparable to the half-life of BPO at the boiling point of chloroform [22]. No evidence for cross-linking was found even after $24 \mathrm{~h}$ at reflux.

In previous work from these laboratories [23], we have studied the graft copolymerization of methacrylates and acrylates onto SBS. In order to identify the site at which graft copolymerization occurs on the SBS, we have studied cross-linking of this material using various initiators. With BPO cross-linking occurs while no cross-linking is observed with azobisisobutyronitrile, AIBN. The explanation which has been offered is based upon the observations [24], [25] that the AIBN radical is unable to remove a hydrogen atom from the majority of polymers while the radical from BPO can easily hydrogen abstract. This explanation was supported by the identification of the site of graft copolymerization. With BPO as initiator reaction occurred by the interaction of monomer with a radical which was formed by removal of an allylic hydrogen from a butadiene unit while for AIBN initiation the reaction occurred through the interaction of a macroradical from the monomer with the double bond of the butadiene. The same reaction must occur in this case so cross-linking occurs with BPO by removal of an allylic hydrogen atom and subsequent coupling of these radicals. The absence of cross-linking with DCP and TBP is mysterious since both are known to be capable of hydrogen abstraction [5], [26].

\subsubsection{The effect of cross-linking on thermal stability}

All three cross-linked polymers, PBD, SBS, and K-resin, begin to degrade earlier than the virgin polymer; the TGA and DSC curves are quite similar to those obtained for the thermally cross-linked samples. It appears that the mode by which cross-linking is accomplished has little effect on the thermal stability of the materials. 


\subsection{Initiator-enhanced thermal cross-linking}

\subsubsection{Cross-linking behavior}

In order to achieve a high cross-link density by a thermal process, a relatively high temperature is required. On the other hand, one can effect cross-linking using an initiator in solution at much more modest temperatures. In an attempt to merge these two processes the crosslinking reaction was carried out using an intimate polymer-initiator blend at somewhat modest temperatures. Two initiators, BPO and DCP, have been used; the half-lives for BPO at $70^{\circ} \mathrm{C}$ and DCP at $120^{\circ} \mathrm{C}$ are similar so reactions have been performed at these temperatures [22]. From the results on the purely thermal cross-linking reaction, one can access the effects of these temperatures and evaluate the relative effectiveness of the initiator on the thermal reaction. The reactions were performed only under vacuum conditions and the amount of initiator was relatively high. Cross-linking occurs quite facilely for all three butadiene-containing polymers and the highest cross-link densities are observed with this procedure. The results are shown in Table 4.

Table 4. Gel contents and swelling ratios for PBD, SBS, K-resin, and polystyrene which have been cross-linked by an initiator-enhanced thermal process

\begin{tabular}{|lllllll|}
\hline $\begin{array}{l}\text { Time } \\
\text { (h) }\end{array}$ & $\begin{array}{c}\text { PBD (\% } \\
\text { GC) }\end{array}$ & $\begin{array}{c}\text { PBD (\% } \\
\text { SR) }\end{array}$ & $\begin{array}{c}\text { SBS (\% } \\
\text { GC) }\end{array}$ & $\begin{array}{c}\text { SBS (\% } \\
\text { SR) }\end{array}$ & $\begin{array}{c}\text { K-resin (\% } \\
\text { GC) }\end{array}$ & $\begin{array}{c}\text { K-resin (\% } \\
\text { SR) }\end{array}$ \\
BPO Initiation at $70^{\circ}$ C & & & & & \\
0 & 0 & $\infty$ & 0 & $\infty$ & 0 & $\infty$ \\
1 & 66 & 3800 & 0 & $\infty$ & & $\infty$ \\
3 & 99 & 1100 & 48 & 2500 & 79 & 2600 \\
6 & 99 & 900 & 90 & 1800 & 95 & 2300 \\
12 & 99 & 800 & 99 & 900 & 98 & 1700 \\
24 & 99 & 700 & 98 & 800 & 99 & 1400 \\
$D C P$ & Initiation at $120^{\circ} \mathrm{C}$ & & & & \\
0 & 0 & $\infty$ & 0 & $\infty$ & 0 & $\infty$ \\
1 & 90 & 800 & 85 & 900 & 88 & 1400 \\
3 & 92 & 300 & 92 & 400 & 90 & 900 \\
6 & 99 & 200 & 98 & 200 & 99 & 500 \\
12 & 99 & 200 & 94 & 200 & 99 & 200 \\
24 & 99 & 100 & 99 & 200 & 99 & 200 \\
\hline
\end{tabular}

When the cross-linking reaction is carried out by a strictly thermal process in vacuum no crosslinking was observed for any of the polymers at $100^{\circ} \mathrm{C}$ and only PBD would cross-link at $150^{\circ} \mathrm{C}$ and this reaction required a minimum of 2 days. It seems clear that the cross-linking which occurs must be due largely to the presence of the initiator but there may be a modest thermal contribution, especially considering the enhanced cross-linking with $\mathrm{DCP}$ at $120^{\circ} \mathrm{C}$ relative to 
that seen for BPO at $70^{\circ} \mathrm{C}$. It is surprising that DCP would not effect cross-linking in tetrachloroethylene solution but will in the absence of solvent. This likely indicates that DCP has a different reactivity in solution versus in the solid state. Since it is known that BPO will remove an allylic hydrogen atom in solution, it is assumed that the same reaction occurs in the solid state for BPO.

The infrared spectra of the cross-linked polymers provides some information on the course of the cross-linking reaction. The olefinic $\mathrm{C}-\mathrm{H}$ stretch frequency at $3007 \mathrm{~cm}^{-1}$ diminishes in intensity for samples cross-linked using DCP but shows little change when BPO is used. This may mean that a portion of the DCP functions by addition to the double bond while BPO effects the removal of an allylic hydrogen atom. The thermal cross-linking of PBD in the presence of DCP has been studied in the literature ${ }^{[27]}$ using solid state ${ }^{13} \mathrm{C}$ NMR and FTIR. The network structure that has been suggested largely supports cross-linking through allylic carbons with a small contribution from the opening of double bonds. A new band appears at $965 \mathrm{~cm}^{-1}$ and the band at $740 \mathrm{~cm}^{-1}$ becomes weaker in the samples prepared using DCP; these features are not observed when BPO is used. This indicates that some isomerization has occurred in the DCP samples.

\subsubsection{The effect of cross-linking on thermal stability}

The initiator-enhanced thermal cross-linking reaction does appear to slightly enhance the thermal stability of PBD. The TGA curves for BPO initiation are shown in Fig. 4. There is essentially no difference between BPO and DCP initiated cross-linking. It is true that the onset of degradation is slightly earlier after cross-linking but this may be due to the formation of volatiles which will normally occur when a sample is heated with an initiator. The significant feature of these curves is that the major degradation step is moved to a slightly higher temperature and the fraction of non-volatile residue is also enhanced. Both SBS and K-resin show similar TGA curves, i.e. a slight increase in the temperature of the major degradation step and a small increase in the fraction of non-volatile residue. TGA/FTIR studies on PBD and PBD which has been cross-linked with both BPO and DCP reveal that there is little difference in the evolution of volatiles upon cross-linking. The same materials are evolved and at essentially the same temperatures. 


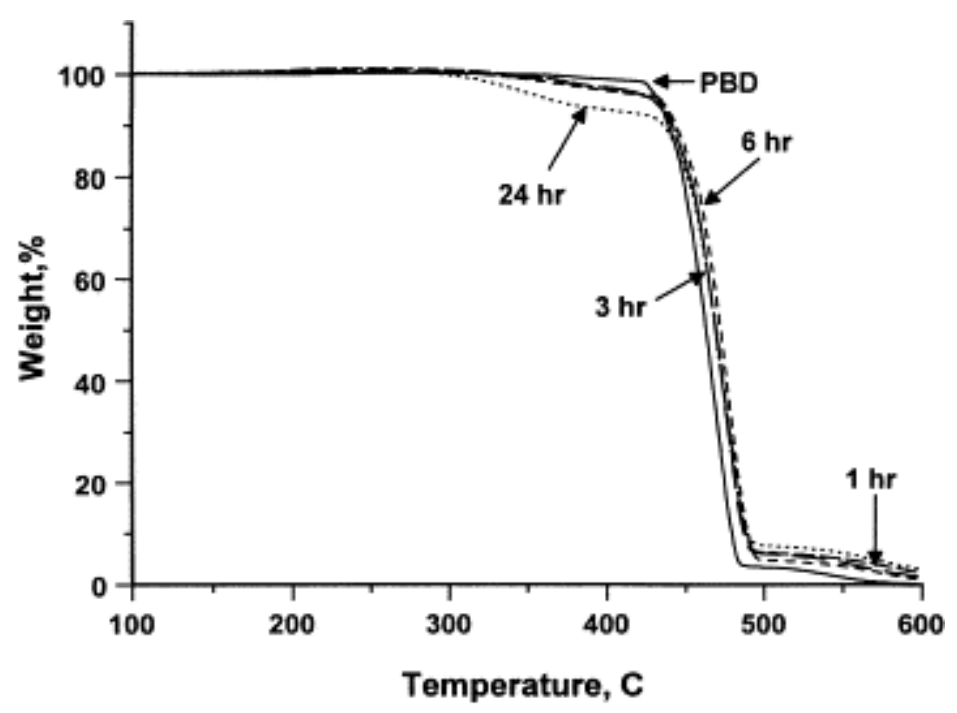

Fig. 4. TGA curves for PBD which has been cross-linked thermally in the presence of BPO.

The DSC curves for unreacted PBD and samples which have been cross-linked with BPO and with DCP are shown in Fig. 5, Fig. 6, respectively. In unreacted PBD there is a small endothermic feature at about $220^{\circ} \mathrm{C}$ due to cis-trans isomerization and another feature at about $400^{\circ} \mathrm{C}$ which has been assigned to cyclization reactions. When the polymers are crosslinked with $\mathrm{BPO}$ the feature at $220^{\circ} \mathrm{C}$ due to isomerization vanishes but cyclization continues and the degradation endotherm is unchanged. When cross-linking is accomplished using DCP as initiator, the DSC curves show some difference. A new feature at $190^{\circ} \mathrm{C}$ appears and the feature due to cyclization vanishes; it is impossible to tell if the feature due to isomerization remains or not due to the width of the $190^{\circ} \mathrm{C}$ band. This feature at $190^{\circ} \mathrm{C}$ is also present in both SBS and K-resin samples cross-linked with DCP. It is not possible to identify this feature in the DSC curve at this time but it is likely in some way connected with the presence of DCP in the samples. The peak due to cyclization vanishes into the baseline for DCP initiation but is unchanged for BPO initiation. The degradation endotherm increases by about $10^{\circ} \mathrm{C}$ for DCP but is unchanged when BPO is used. The fact that the cyclization feature vanishes when the polymer is cross-linked with DCP implies that the cross-linking reaction occurs to a large extent and this is reflected in the quite low swelling ratios for DCP initiation as compared to BPO initiation. 


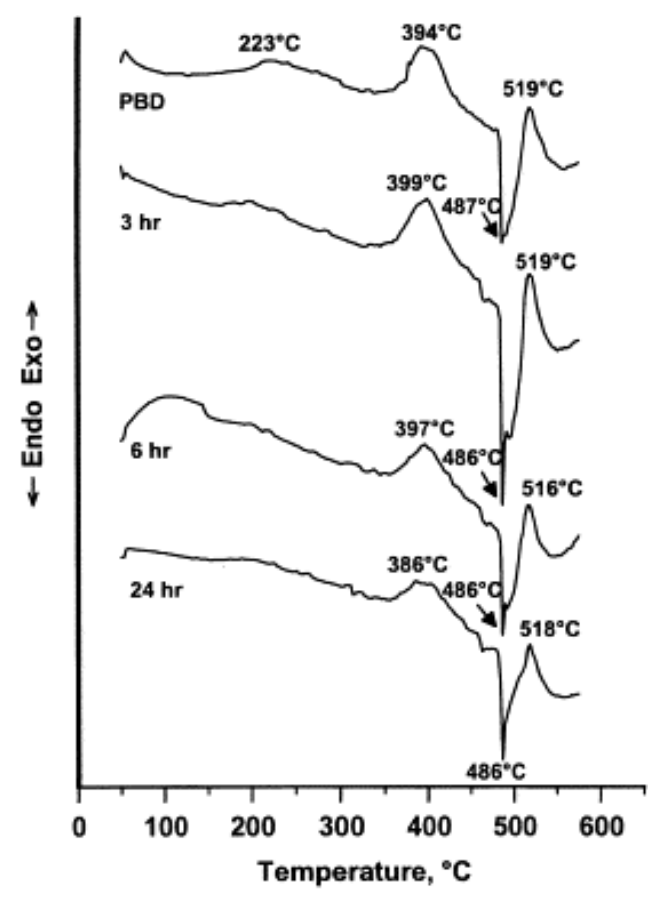

Fig. 5. DSC curves for PBD cross-linked with BPO for the indicated time period.

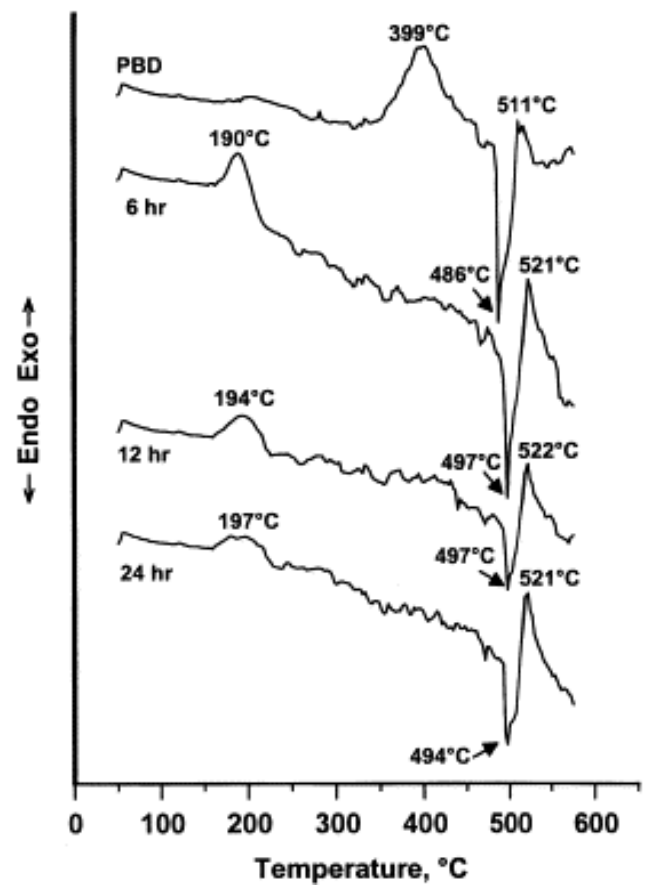

Fig. 6. DSC curves for PBD which has been cross-linked with DCP for the indicated time period. 


\section{Conclusion}

While many processes will accomplish the goal of cross-linking PBD and copolymers containing butadiene, the most efficient process is the initiator assisted thermal process. The cyclization step which has been previously described as occurring in PBD occurs even in polymer which have a somewhat high cross-link density. Only PBD which has been crosslinked using dicumyl peroxide in a blend with PBD gives a high enough cross-link density so that the cyclization step is inhibited. Cross-linking has no advantageous effect on the onset temperature of the degradation, in fact, invariably the onset temperature is lowered, presumably because a significant number of small, volatile molecules are produced from the radicals involved in the cross-linking reaction. It is only with initiator-assisted thermal crosslinking that the entire degradation does not proceed at an earlier time than in the uncrosslinked polymer; this is likely do to the higher cross-link densities which are achieved in this reaction.

\section{Acknowledgements}

This work has been financially supported in part by a NATO Linkage grant OUTR.LG960310. The cooperation of Dun Chen and the Cahn Instrument Company in making their TGA/FTIR equipment available for this study is gratefully acknowledged.

\section{References}

1 W. Schnabel, G.C. Levchik, C.A. Wilkie, D.D. Jiang, S.V. Levchik Polym. Degrad. Stab., 63 (1999), p. 365

2 P.J. Flory, J. Renner J. Chem. Phys., 11 (1943), p. 512

3 P.J. Flory, J. Renner J. Chem. Phys., 11 (1943), p. 521

4 K. Matsuka, A. Tanaka, I. Murakami Polymer, 25 (1984), p. 1337

5 C.G. Moore, J. Scanlan J. Polym. Sci., 43 (1960), p. 23

6 W.W. Parkinson, R.M. KeyserPolystyrene and related polymers M Dole (Ed.), The radiation chemistry of macromolecules, vol. II, Academic Press, New York (1972), p. 57

7 G.G.A. BohnThe radiation chemistry of elastomers

$8 \mathrm{M}$. Dole (Ed.), The radiation chemistry of macromolecules, vol. II, Academic Press, New York (1972), p. 195

9 R.T. ConleyInfrared spectroscopy (2nd ed.), Allyn and Bacon, Boston (MA) (1972)

10 M.A. Golub, R.J. Gargiulo J. Polym. Sci., Polym. Lett. Ed., 10 (1972), p. 41

11 Golub MA. In: Grassie N, editor. Developments in polymer degradation, vol. 4. London:

Applied Science, 1982. p. 27-69.

12 M.A. Golub J. Polym. Sci., Polym. Lett. Ed., 12 (1974), p. 615

13 N. Grassie, A. Heaney Eur. Polym. J., 10 (1974), p. 415

14 N. Grassie, A. Heaney J. Polym. Sci., Polym. Lett. Ed., 12 (1974), p. 89

15 K. McCreedy, H. Keskkula Polymer, 1115 (1979), p. 20

16 K. McCreedy, H. Keskkula J. Appl. Polym. Sci., 22 (1978), p. 999 
17 X.-R. Zeng, T.-M. Ko J. Appl. Polym. Sci., 67 (1998), p. 2131

18 Bovey FA, Jelinski LW. Chain structure and conformation of macromolecules. Academic Press, 1982. p. 101-2.

19 M. Rama Rao, T.S. Radhakrishan J. Appl. Polym. Sci., 41 (1990), p. 2251

20 Grassie N, Scott G. Polymer degradation and stabilization. Cambridge: Cambridge University Press, 1985. p. 90.

21 Grassie N, Scott G. Polymer degradation and stabilization. Cambridge: Cambridge University Press, 1985. p. 108-11.

22 T.J. Xue, C.A. Wilkie J. Polym. Sci. A: Polym. Chem., 35 (1997), p. 1275

23 Macon JC. In: Brandrup J, Immergut EH, editors. Polymer handbook. 3rd ed. New York: Wiley, 1989. p. II 1-65.

24 D.D. Jiang, C.A. Wilkie J. Polym. Sci. A: Polym. Chem., 35 (1997), p. 965

25 J.C. Bevington J. Chem. Soc., London, 4 (1954), p. 3707

26 Seymour RB, Carraher CE Jr. Polymer chemistry. 3rd ed. New York: Dekker. p. 324.

27 C.G. Moore, W.F. Watson J. Polym. Sci., 19 (1956), p. 237

28 Patterson DJ, Koenig, JL. In: Labana SS, Dickie RA, editors. Characterisation of highly cross-linked polymers. ACS Symp. Ser. 243. Washington, 1984. p. 205-32. 